University of Nebraska - Lincoln

DigitalCommons@University of Nebraska - Lincoln

Publications from USDA-ARS / UNL Faculty

U.S. Department of Agriculture: Agricultural

Research Service, Lincoln, Nebraska

2010

\title{
Evaluation Of ULV And Thermal Fog Mosquito Control Applications In Temperate And Desert Environments
}

\author{
Seth C. Britch \\ USDA-ARS, Seth.Britch@ars.usda.gov \\ Kenneth J. Linthicum \\ United States Department of Agriculture \\ Wayne W. Wynn \\ United States Department of Agriculture \\ Todd W. Walker \\ Navy Entomology Center of Excellence \\ Muhammad Farooq \\ Navy Entomology Center of Excellence \\ See next page for additional authors \\ Follow this and additional works at: https://digitalcommons.unl.edu/usdaarsfacpub \\ Part of the Agricultural Science Commons
}

Britch, Seth C.; Linthicum, Kenneth J.; Wynn, Wayne W.; Walker, Todd W.; Farooq, Muhammad; Smith, Vincent L.; Robinson, Cathy A.; Lothrop, Branka B.; Snelling, Melissa; Gutierrez, Arturo; Lothrop, Hugh D.; Kerce, Jerry D.; Becnel, James J.; Bernier, Ulrich R.; and Pridgeon, Julia W., "Evaluation Of ULV And Thermal Fog Mosquito Control Applications In Temperate And Desert Environments" (2010). Publications from USDA-ARS / UNL Faculty. 954.

https://digitalcommons.unl.edu/usdaarsfacpub/954

This Article is brought to you for free and open access by the U.S. Department of Agriculture: Agricultural Research Service, Lincoln, Nebraska at DigitalCommons@University of Nebraska - Lincoln. It has been accepted for inclusion in Publications from USDA-ARS / UNL Faculty by an authorized administrator of DigitalCommons@University of Nebraska - Lincoln. 


\section{Authors}

Seth C. Britch, Kenneth J. Linthicum, Wayne W. Wynn, Todd W. Walker, Muhammad Farooq, Vincent L. Smith, Cathy A. Robinson, Branka B. Lothrop, Melissa Snelling, Arturo Gutierrez, Hugh D. Lothrop, Jerry D. Kerce, James J. Becnel, Ulrich R. Bernier, and Julia W. Pridgeon 


\title{
EVALUATION OF ULV AND THERMAL FOG MOSQUITO CONTROL APPLICATIONS IN TEMPERATE AND DESERT ENVIRONMENTS
}

\author{
SETH C. BRITCH, ${ }^{1}$ KENNETH J. LINTHICUM, ${ }^{1}$ WAYNE W. WYNN, ${ }^{1}$ TODD W. WALKER, ${ }^{2}$ \\ MUHAMMAD FAROOQ, ${ }^{2}$ VINCENT L. SMITH, ${ }^{2}$ CATHY A. ROBINSON,${ }^{2}$ BRANKA B. LOTHROP, ${ }^{3}$ \\ MELISSA SNELLING,${ }^{3}$ ARTURO GUTIERREZ, ${ }^{3}$ HUGH D. LOTHROP, ${ }^{4}$ JERRY D. KERCE,

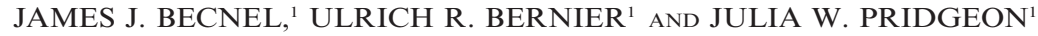

\begin{abstract}
Ultra-low-volume (ULV) and thermal fog aerosol dispersals of pesticides have been used against mosquitoes and other insects for half a century. Although each spray technology has advantages and disadvantages, only 7 studies have been identified that directly compare their performance in the field. US military personnel currently operating in hot-arid environments are impacted by perpetual nuisance and disease vector insect problems, despite adulticide operations using modern pesticide-delivery equipment such as ULV. None of the identified comparative studies has looked at the relative feasibility and efficacy of ULV and thermal fog equipment against mosquitoes in hot-arid environments. In this study we examine the impact of ULV and thermal fog applications of malathion against caged sentinel mosquitoes in the field in a warm temperate area of Florida, followed by a similar test in a hot-dry desert area of southern California. Patterns of mortality throughout $150 \mathrm{~m} \times 150 \mathrm{~m}$ grids of sentinel mosquitoes indicate greater efficacy from the thermal fog application in both environments under suboptimal ambient weather conditions. We discuss the implications of these findings for future military preventive medicine activities and encourage further investigations into the relative merits of the 2 technologies for force health protection.
\end{abstract}

KEY WORDS Coachella Valley, Camp Blanding, aerosol pesticide delivery, malathion, Deployed WarFighter Protection Program

\section{INTRODUCTION}

For more than 60 years, spray dispersal of aerosolized insecticides has been a critical weapon against nuisance insects and insect vectors of disease. Two technologies have dominated this approach and continue to be used throughout the world: thermal fogging, originating from military smoke generators in the early 1940s (LaMer et al. 1947), and ultra-low-volume (ULV) "cold mist" spraying, originating from modifications to standard agricultural sprayers in the 1950s (Lofgren 1970). Numerous pesticides formulated for use in thermal foggers and ULV sprayers have evolved, as have spray technologies such as those cited in Mount (1998) and Hoffmann et al. (2007a, 2007b, 2008). The US military depends on aerosol dispersal of adulticides for sand fly and mosquito control in hot, dry, and dusty environments in the Middle East. However, the dwindling list of Environmental Protection Agency-approved pesticides available for military use (Armed Forces

${ }^{1}$ United States Department of Agriculture, Agricultural Research Service, Center for Medical, Agricultural, and Veterinary Entomology, 1600 SW 23rd Drive, Gainesville, FL 32608.

${ }^{2}$ Navy Entomology Center of Excellence, Naval Air Station, PO Box 43, Jacksonville, FL 32212.

${ }_{3}^{3}$ Coachella Valley Mosquito and Vector Control District, 43-420 Trader Place, Indio, CA 92201.

${ }^{4}$ Arbovirus Research Unit, Center for Vectorborne Diseases, School of Veterinary Medicine, University of California, Davis, CA 95616.

${ }^{5}$ Camp Blanding Joint Training Site, 5629 State Road 16W, Starke, FL 32091.
Pest Management Board 2010) and failure to control nuisance and vector insect problems in recent desert military operations underscore the need to reexamine current control strategies (Linthicum et al. 2007, Cope et al. 2008, Dalton 2008).

A survey of the literature between 1940 and 2009 reveals an asymmetry between assessments of thermal fog and ULV technology. Hundreds of research studies on ULV efficacy against a range of insects have been carried out, whereas only dozens exist for thermal fog technology. Only 7 studies have been identified comparing ULV and thermal fog efficacy against mosquitoes in outdoor applications (Mount et al. 1968, Mount et al. 1970, Taylor and Schoof 1971, Rathburn and Boike 1972, Phanthumachinda et al. 1976, Wirat et al. 1982, Linley and Jordan 1992). In these 7 studies, thermal fogging frequently performed comparably to ULV, yet current practices in US mosquito abatement agencies and US military doctrine emphasize the use of ULV. Contributing factors for ULV preference by mosquito abatement agencies is the lower volume of material dispersed in the environment, quieter operation, and lack of visible "smoke" compared to thermal fogging, all of which are also important factors in military pest management scenarios. However, renewed interest in optimizing aerosol pesticide efficacy in militarily relevant desert environments, especially given the current difficulty of controlling sand fly and mosquito populations with ULV in these environments, leads to the comparative examination of these 2 technologies in this study. 


\section{Report Documentation Page}

Public reporting burden for the collection of information is estimated to average 1 hour per response, including the time for reviewing instructions, searching existing data sources, gathering and maintaining the data needed, and completing and reviewing the collection of information. Send comments regarding this burden estimate or any other aspect of this collection of information, including suggestions for reducing this burden, to Washington Headquarters Services, Directorate for Information Operations and Reports, 1215 Jefferson Davis Highway, Suite 1204, Arlington VA 22202-4302. Respondents should be aware that notwithstanding any other provision of law, no person shall be subject to a penalty for failing to comply with a collection of information if it does not display a currently valid OMB control number.

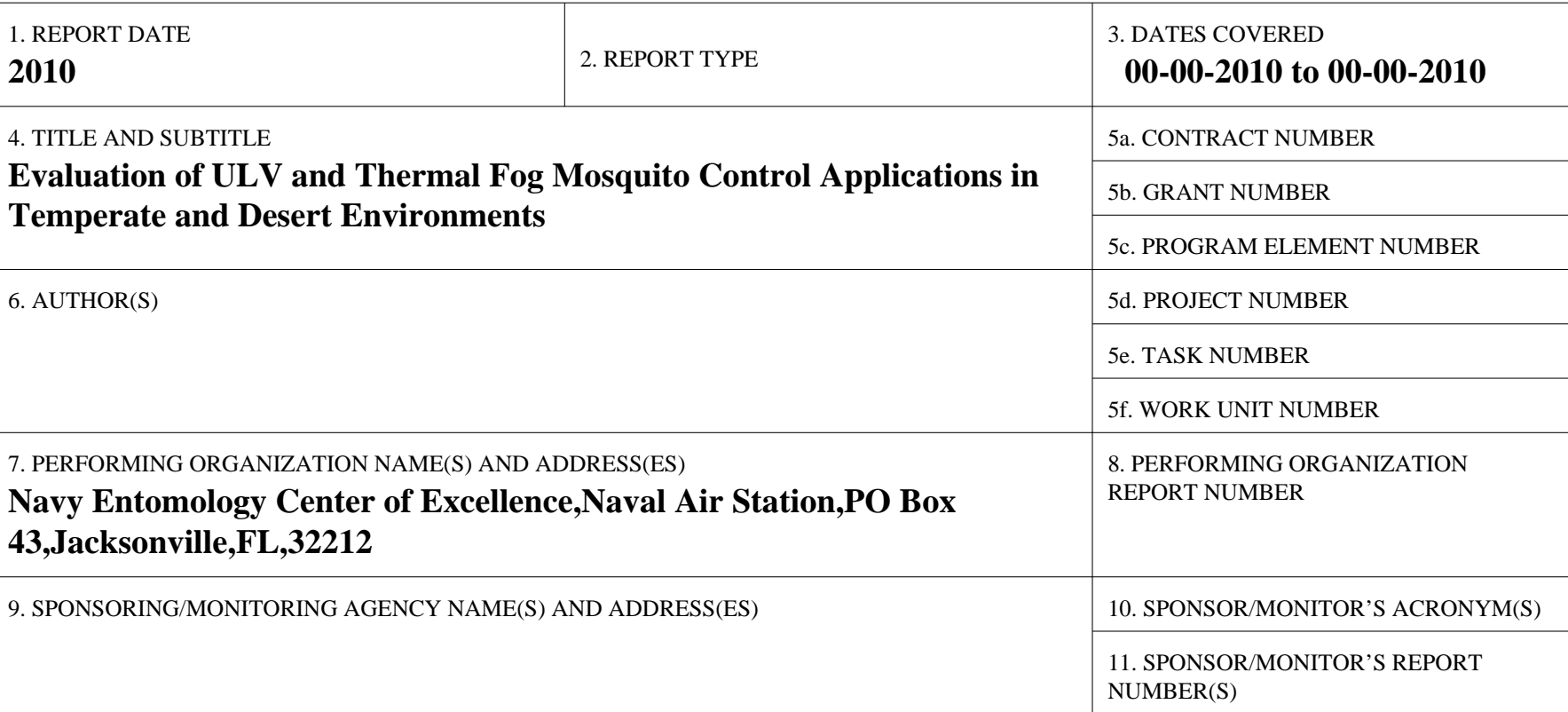

12. DISTRIBUTION/AVAILABILITY STATEMENT

Approved for public release; distribution unlimited

13. SUPPLEMENTARY NOTES

14. ABSTRACT

Ultra-low-volume (ULV) and thermal fog aerosol dispersals of pesticides have been used against mosquitoes and other insects for half a century. Although each spray technology has advantages and disadvantages, only 7 studies have been identified that directly compare their performance in the field. US military personnel currently operating in hot-arid environments are impacted by perpetual nuisance and disease vector insect problems, despite adulticide operations using modern pesticide-delivery equipment such as ULV. None of the identified comparative studies has looked at the relative feasibility and efficacy of ULV and thermal fog equipment against mosquitoes in hot-arid environments. In this study we examine the impact of ULV and thermal fog applications of malathion against caged sentinel mosquitoes in the field in a warm temperate area of Florida, followed by a similar test in a hot-dry desert area of southern California. Patterns of mortality throughout $150 \mathrm{~m} 3150 \mathrm{~m}$ grids of sentinel mosquitoes indicate greater efficacy from the thermal fog application in both environments under suboptimal ambient weather conditions. We discuss the implications of these findings for future military preventive medicine activities and encourage further investigations into the relative merits of the 2 technologies for force health protection.

15. SUBJECT TERMS

16. SECURITY CLASSIFICATION OF:

a. REPORT

unclassified b. ABSTRACT unclassified c. THIS PAGE unclassified
17. LIMITATION OF ABSTRACT

Same as Report (SAR)
18. NUMBER OF PAGES

15 19a. NAME OF RESPONSIBLE PERSON 
In addition, all previous ULV/thermal fog comparative studies were conducted in warm, moist temperate or tropical areas such as Georgia, Florida, and 2 locations in Thailand. Given 17 years of improvements in technology and chemical formulations since the most recent of the studies, a better understanding of factors that contribute to the relative efficacy, feasibility, and limitations of the 2 technologies in hot-arid environments is needed.

In this study we assessed the relative efficacy of ULV and thermal fog applications to control Culex and Aedes adults in temperate and desert environments. Multiple factors including environmental conditions have a significant impact upon the efficacy of aerosols used in adult mosquito control operations; for instance, hotarid climates are likely to be particularly problematic because of impacts such as rapid evaporation. No studies have been identified that look at the performance of thermal fog in hot, dry conditions; however, ground and aerial ULV aerosol pesticide delivery in hot dry conditions has been carried out with mixed outcomes against desert locusts (Holland and Jepson 1996) and mosquitoes (Lothrop et al. 2007a, 2007b, Lothrop et al. 2008), in part because of population dynamics or wind conditions at the time of delivery. No studies have been identified that investigate differences in success of ULV or thermal fog (or ULV and thermal fog side by side) applications in hot, dry compared to warm, moist conditions, regardless of wind conditions. We carried out an initial trial of the experiment in a warm, moist temperate area in northern Florida to evaluate the feasibility of the experimental design and obtain a baseline for performance of the 2 technologies. The second trial was nearly identical in design to the first, but carried out in a desert area in southern California as a proxy for environmental conditions in current US military operations in most regions of Iraq and many regions of Afghanistan.

\section{METHODS AND MATERIALS}

We measured the efficacy of ULV and thermal fog spray technologies by way of 2 assays, including spatial patterns of mortality in sentinel mosquito cages placed on test grids in the aerosol cloud, and droplet density and deposition on paper ribbons placed within the test grids.

\section{Study sites}

We conducted the initial baseline field study in a temperate habitat in Camp Blanding $(29.864890 \mathrm{~N}, 81.973534 \mathrm{~W}, 210 \mathrm{ft})$, a military reservation in northern Florida within $60 \mathrm{~min}$ travel distance from the Center for Medical, Agricultural, and Veterinary Entomology labora-

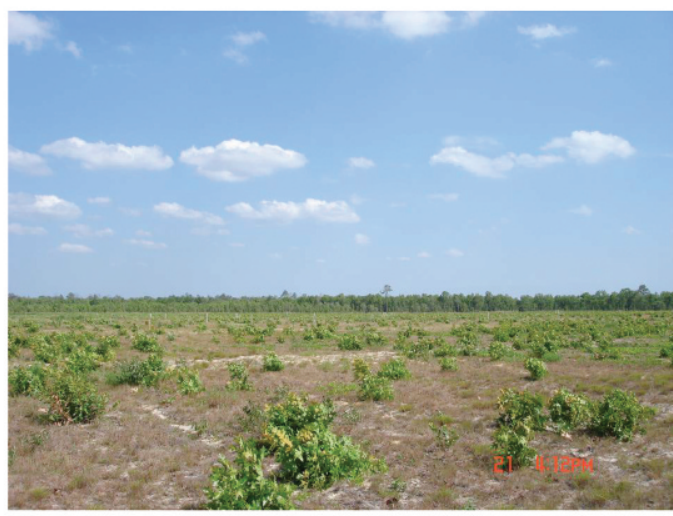

B

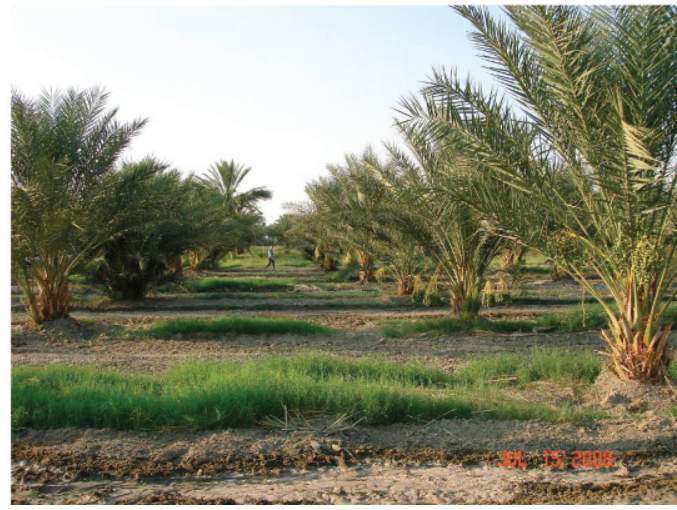

Fig. 1. (A) Typical view of the habitat at Camp Blanding, FL: open ground with sparse forb vegetation; clear, breezy, warm, humid. (B) Typical view of the habitat in the date palm grove in the Coachella Valley, CA: rows of planted date palms; clear, breezy, hot, and dry.

tory, and conducted the follow-up field study in a date palm desert habitat in the Coachella Valley in southern California $(33.607660 \mathrm{~N}, 116.213721 \mathrm{~W}$, $-97 \mathrm{ft}$ ), within $60 \mathrm{~min}$ travel distance from the Coachella Valley Mosquito and Vector Control District laboratory. The Florida site was open, level, and clear of any vegetation over $\sim 0.5 \mathrm{~m}$ tall (Fig. 1A). The California site was level with regular rows of date palm trees $\sim 3-5 \mathrm{~m}$ tall and low understory vegetation consisting mostly of grass $\sim 0.25 \mathrm{~m}$ tall (Fig. 1B). In both areas we used identical ULV and thermal fog equipment and a single pesticide formulation.

\section{Spray materials}

In both study areas we used Fyfanon ULV (Cheminova, Wayne, NJ) malathion pesticide at $100 \%$ in all ULV applications and in a 5.9\% solution in diesel in all thermal fog applications. 
The label recommends an application rate of 24 oz/acre $(\sim 148-296 \mathrm{ml} / \mathrm{ha})$. We added an ultraviolet (UV) fluorescent tracer dye to the pesticide to permit detection of spray on capture apparatus, described below. For the experiment conducted at the Florida site we mixed Uvitex OB fluorescent dye (Ciba Corporation, Newport, DE) with the Fyfanon ULV at 2,000 ppm for the ULV application and at $1,000 \mathrm{ppm}$ for the thermal fog application. Subsequent observations at the Florida site indicated that labeled droplets from the ULV trial were not visible, and labeled droplets from the thermal fog trial were only weakly visible with a UV flashlight. Thus, for the experiment conducted at the California site, the dye concentrations were increased $100 \%$ to $4,000 \mathrm{ppm}$ for the ULV application and $50 \%$ to $1,500 \mathrm{ppm}$ for the thermal fog application.

\section{Sprayers}

We used the London Fog 18-20 (London Fog, Long Lake, MN) ULV aerosol generator and the Curtis Dyna-Fog Silver Cloud model 2560 (Curtis Dyna-Fog, Westfield, IN) thermal fogger in this study. Both pieces of equipment were vehicle-mounted, and in both the Florida and California trials the ULV sprayer was used to spray the west plots, and the thermal fogger was used to spray the east plots.

The 18-20 ULV aerosol generator is powered by an $18 \mathrm{hp}(13.2 \mathrm{~kW})$ gasoline engine and is equipped with an air-shear nozzle. The ULV has a net weight of $445 \mathrm{lb}(202 \mathrm{~kg})$. The air source is a rotary, positive-displacement blower that can produce air flow up to $356 \mathrm{ft}^{3}\left(10.1 \mathrm{~m}^{3}\right)$ per minute, and the nozzle provides $360^{\circ}$ rotation both horizontally and vertically. The liquid flow rate ranges from 0 to $22 \mathrm{oz}$ ( 0 to 0.65 liter) per minute, and the tank capacity is 15 gallons (56 liter) with a 0.4 gallon (1.58 liter) flush tank. For this study, we set the sprayer nozzle to discharge horizontally, parallel to and away from the direction of travel. We set the flow rate at $10.7 \mathrm{oz} / \mathrm{min}(316 \mathrm{ml} / \mathrm{min})$, and we drove the sprayer mounted on a pickup truck at $10 \mathrm{mph}$ $(16 \mathrm{~km} / \mathrm{h})$ to produce an application rate of $1.77 \mathrm{oz} / \mathrm{acre}(0.129$ liter/ha) of total solution and an application rate of active ingredient of $1.71 \mathrm{oz} /$ acre $\left(0.125\right.$ liter/ha). The $18-20$ produces a $\mathrm{D}_{\mathrm{v} 0.1}$, $\mathrm{D}_{\mathrm{v} 0.5}, \mathrm{D}_{\mathrm{v} 0.9}$, of $6.1,14.6$, and $26.6 \mu \mathrm{m}$, respectively, and $72.7 \%$ of the spray volume is made up of droplets $\leq 20 \mu \mathrm{m}$ (Hoffmann et al. 2007a).

The Silver Cloud uses gasoline-powered $88 \mathrm{hp}$ $(66 \mathrm{~kW})$ twin pulse jet engines to produce a thermal fog. The thermal fogger has a net weight of $106 \mathrm{lb}(48 \mathrm{~kg})$ and a fuel tank capacity of $6 \mathrm{gal}$ (9.5 liter). The fogger can deliver up to $40 \mathrm{gal} / \mathrm{h}$ $\left(151.4\right.$ liter/h) and produce over $250,000 \mathrm{ft}^{3}$ $\left(6,500 \mathrm{~m}^{3}\right)$ of effective fog per minute. For this study we set the machine to deliver $85.3 \mathrm{oz} / \mathrm{min}$

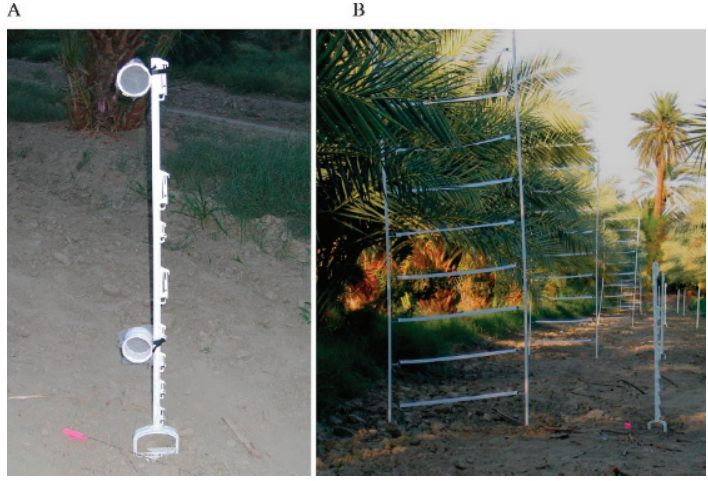

Fig. 2. (A) Upright plastic fence post with 2 sentinel cages attached at $0.3 \mathrm{~m}$ and $1.2 \mathrm{~m}$ above ground. (B) The ribbon ladder apparatus, shown deployed alongside sentinel cage poles in the California date palm habitat.

(2.5 liter/min). The thermal fogger was mounted on an ATV (Florida trial) or a flat bed truck (California trial) and operated at $5 \mathrm{mph}(8 \mathrm{~km} / \mathrm{h})$ to produce an application rate of 28.1 oz/acre (2.0 liter/ha) of pesticide diluted with diesel to $5.9 \%$ in solution, and an active ingredient application rate of $1.60 \mathrm{oz} /$ acre $(0.114$ liter/ha). The fogger produces a $\mathrm{D}_{\mathrm{v} 0.1}, \mathrm{D}_{\mathrm{v} 0.5}, \mathrm{D}_{\mathrm{v} 0.9}$, of 1.0 , 3.1 , and $6.0 \mu \mathrm{m}$, respectively, and $100 \%$ of the fog volume is made up of droplets $\leq 20 \mu \mathrm{m}$ (Hoffmann et al. 2008).

\section{Test grids of sentinel mosquito cages}

To measure efficacy of ULV and thermal fog applications we set up $150 \mathrm{~m} \times 150 \mathrm{~m}$ grids of caged sentinel mosquitoes based on the experimental design first outlined by Rogers et al. (1957). We delineated grids using 1-m resolution 3-band (RGB) natural color Digital Orthophoto Quadrangles (DOQs; available from the US Geological Survey, http://seamless.usgs.gov/) in the ArcGIS 9.2 (Environmental Systems Research Institute, Redlands, CA) geographic information system (GIS). Grids for the ULV application and the thermal fog application were separated by at least $125 \mathrm{~m}$ to preclude crosscontamination by the insecticide. Each grid consisted of 25 upright posts (Fig. 2A) - either 2-in.-diam PVC pipes (Florida test) or plastic fence poles (California test) - arrayed in a regular pattern of increasing distance from the spray line (Fig. 3), upon which were mounted sentinel mosquito cages at $0.3 \mathrm{~m}$ and $1.2 \mathrm{~m}$. The locations for the 25 posts were surveyed using coordinates extracted from the GIS and input into a GeoXT (Trimble, Sunnyvale, CA) handheld geographic position system (GPS) device. The GPS unit provided $\sim 3 \mathrm{~m}$ precision (uncorrected), which was sufficient to quickly stake out the 25 sentinel points, followed by a final straightening of rows by eye based on north-south and east-west 


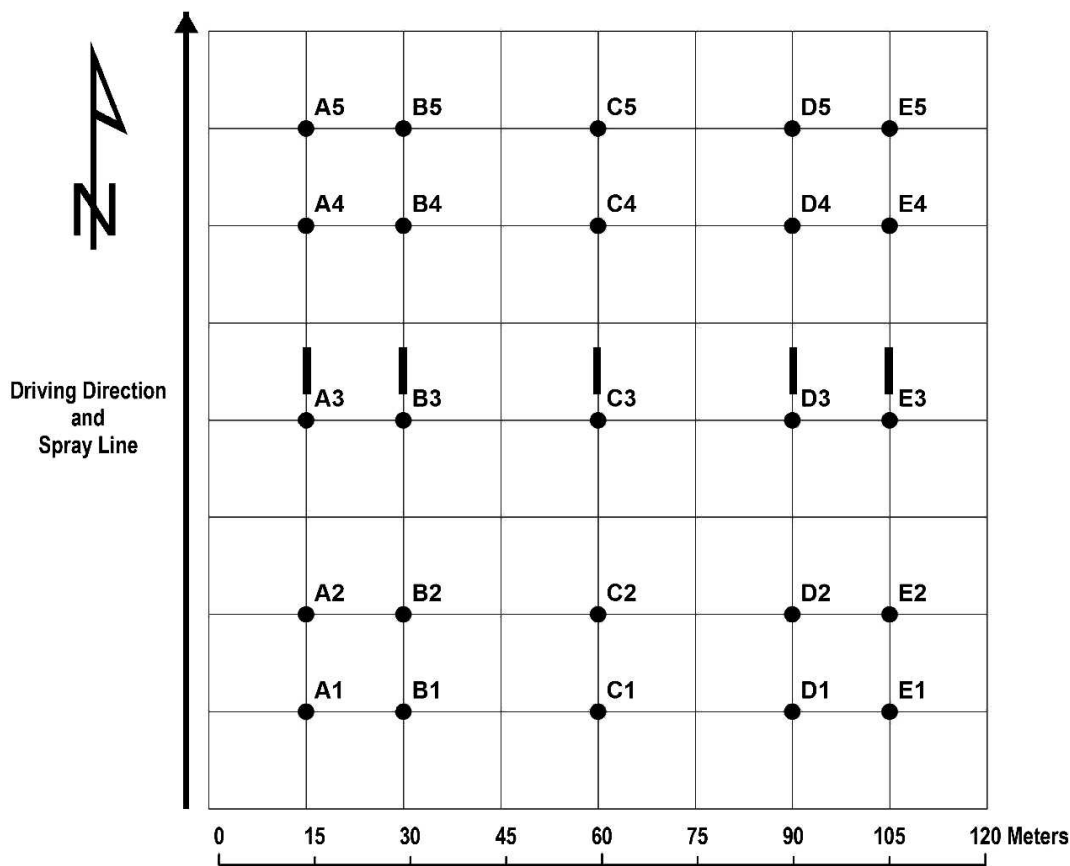

Fig. 3. Aerosol pesticide application test grid, showing driving direction, spray path, and arrangement of the 25 sentinel mosquito poles (A1 through E5). The "ribbon ladder" droplet detection apparatus (represented by short thick black bars) were deployed adjacent to pole positions A3, B3, C3, D3, and E3 (refer to Fig. 2B image).

reference lines measured on the ground using a 200-m measuring tape. We set the GPS at the NAD 1983 datum for spatial reference to UTM Zone $17 \mathrm{~N}$ (Florida test) or UTM Zone $11 \mathrm{~N}$ (California test) to match the USGS DOQs.

Each sentinel cage contained $\sim 25$ colonyreared female Aedes taeniorhynchus Wiedemann (Florida test) or Culex quinquefasciatus Say (California test). The Ae. taeniorhynchus colony originated from a strain sampled in 1952 in Orlando, FL, and has since been maintained on membranes at the Gainesville laboratories. The colony has not been exposed to pesticides during rearing and is considered a susceptible strain; preliminary tests of oral toxicities with permethrin are comparable to known susceptible colonies of Cx. quinquefasciatus and Ae. aegypti (Allan, personal communication). The $C x$. quinquefasciatus colony originated from a 2004 field collection in Bakersfield (Kern County), California. The colony has not been exposed to pesticides during rearing and is considered a susceptible strain; preliminary tests with pyrethrum and permethrin in bottle bioassays cause death in $\leq 15$ min (Wittie, personal communication). We stored sentinel cages containing mosquitoes in coolers for travel to the field sites and waited until $\sim 30$ min prior to the applications to attach them to the posts. The sentinel cages were cylindrical paper food containers $(8.5 \mathrm{~cm}$ wide $X$ $4.5 \mathrm{~cm}$ deep; Neptune Paper Products, Newark,
NJ) with the paper disk bottom removed, covered by nylon tulle mesh held fast with a rubber band on each end (Fig. 2A). We attached sentinel cages to posts using disposable hook-and-loop cable ties threaded through one of the rubber bands. The design of the assembly permitted the posts to be easily rotated to orient the open ends of the cages with wind direction immediately before the application and thus maximize exposure of the mosquitoes to the aerosol clouds. In both the Florida and California experiments, a set of 5 posts each carrying 2 control mosquito sentinel cages at $0.3 \mathrm{~m}$ and $1.2 \mathrm{~m}$ heights was situated in upwind untreated areas at least $150 \mathrm{~m}$ from the treatment grids.

We applied the insecticide spray in a single swath along the west side of each grid, and ULV and thermal fog applications commenced simultaneously during minimum acceptable wind conditions just before dark, when adulticide operations are typically conducted to coincide with adult mosquito activity. The ambient conditions at the Florida test consisted of the spray line moving downwind (i.e., in the direction the wind was blowing; see Fig. 4); however, at the California test the spray line traveled upwind (i.e., against the direction of the wind; see Fig. 5). We adjusted vehicle speeds to the recommended flow rate for each device so that the single pass would result in identical delivery of active ingredient to both grids. To provide space and time for the 
wind to move the aerosol cloud to potentially reach all posts in the grids, we began the applications with a lead of $40 \mathrm{~m}$ in the Florida trial, owing to the southwesterly winds, and a follow-on of $40 \mathrm{~m}$ in the California trial, owing to the northwesterly winds. The drive path (spray line) was a line parallel to and $50 \mathrm{ft}(15 \mathrm{~m})$ from the first set of sentinel cages. We retrieved all mosquitoes from the field test grids $10 \mathrm{~min}$ postspray and returned them to the laboratory in coolers for transfer to identical pesticide-free cages with a sugar water source (Bunner et al. 1989). Mortality of sentinel mosquitoes was tallied during transfer to the new cages, which was carried out between 1.5 and $2 \mathrm{~h}$ post-spray, and we conducted subsequent observation of mortality under controlled conditions of temperature, light-cycle, and humidity at 12 and $24 \mathrm{~h}$ post-spray. For all transfers of adult mosquitoes into or between cages we used $\mathrm{CO}_{2}$ (Florida trial) or chilling (California trial) to anaesthetize and immobilize the insects.

As an additional measure of efficacy at the California site, we performed mosquito population surveys for local wild Psorophora columbiae populations one night before and one night after the applications using 6 modified Encephalitis Vector Surveillance (EVS) traps (Rohe and Fall 1979) baited with dry ice $\left(\mathrm{CO}_{2}\right)$ without light set throughout the $400 \mathrm{~m} \times 400 \mathrm{~m}$ date palm plantation.

\section{Sampling droplet deposition in the test grids}

To measure airborne spray passing through a vertical plane, we used a specialized apparatus known as the ribbon ladder (Fig. 2B). The ribbon ladder consists of nine $1.0-\mathrm{m}$ lengths of $2.5-\mathrm{cm}-$ wide biodegradable cotton ribbons (Lab Safety Supply, Janesville, WI) stretched horizontally at 1-ft $(0.3 \mathrm{~m})$ intervals across a $10-\mathrm{ft}(3 \mathrm{~m})$-high frame created from $1 / 2$ in. PVC pipe in the shape of an inverted "U." Ribbons were attached with binder clips to L-hooks screwed into the PVC at each interval. We placed 5 ribbon ladders along the centerline of each test plot at 50, 100, 200, 300 , and $350 \mathrm{ft}(15.3,30.5,61.0,91.5$, and $106.7 \mathrm{~m}$ ) from and perpendicular to the spray line, and adjacent to the corresponding centerline sentinel mosquito cages (Figs. 2 and 3). Approximately $30 \mathrm{~min}$ before aerosol applications we deployed all ribbons, and $\sim 10$ min after completion of the treatment, the ribbons were visually examined for the presence of fluorescent drops using a UV flashlight and then were cut near the mount and stored separately in previously labeled plastic bags. We discarded ends of the ribbons touching the L-hook to eliminate contamination from previous applications. We packed the bagged deposition samples in a cooler for transport to the Navy Entomology Center of
Excellence laboratory in Jacksonville, FL, where samples were stored in a refrigerator at $-4^{\circ} \mathrm{C}$ for analysis.

To prepare the ribbons for analysis, we poured $50 \mathrm{~mL}$ of denatured ethanol wash liquid into each bag so that all ribbons were wet, left the ribbons to soak for $5 \mathrm{~min}$, and then placed the bags on a shaker platform to shake for $4 \mathrm{~min}$. The wash solution was then poured into two $10 \mathrm{ml}$ cuvettes for analysis with a Model 700 fluorometer (Turner Design, Sunnyvale, CA). The raw fluorometer readings were converted to dye concentration using calibrations provided from a standard solution. The dye deposition on ribbons was determined with the following formula:

$$
D e p=\frac{1,000 C_{w s} V_{w}}{A_{s}},
$$

where

$$
\begin{aligned}
\text { Dep }= & \begin{array}{l}
\text { Deposition of dye on ribbon surface } \\
\left(\mathrm{ng} / \mathrm{cm}^{2}\right)
\end{array} \\
C_{w s}= & \begin{array}{l}
\text { Concentration of dye in wash solution } \\
(\mathrm{ppm} \text { or } \mu \mathrm{g} / \mathrm{ml})
\end{array} \\
V_{w}= & \text { Wash volume }(\mathrm{ml}) \\
A_{s}= & \begin{array}{l}
\text { Surface area of the ribbon samplers } \\
\text { calculated using dimensions of cut } \\
\text { ribbon }\left(\mathrm{cm}^{2}\right) .
\end{array}
\end{aligned}
$$

We then calculated the deposition of active ingredient on the ribbon using the ratio of active ingredient to dye in the tank mix. For ULV and thermal fogger, these ratios were 593.14 and 70.0 for Florida trials and 339.4 and 34.0 for California trials, respectively. The deposition data in both experiments were comparable, despite the different amounts of Uvitex OB fluorescent dye added, because of the normalization inherent in calculating the ratios.

\section{Weather conditions}

In both Florida and California trials, we measured wind speed, wind direction, and temperature with a Model 8100 3-D ultrasonic anemometer (R. M. Young Company, Traverse City, MI) stationed at a point midway between the 2 spray plots. Wind data were recorded at $10 \mathrm{ft}$ $(3 \mathrm{~m})$ at a frequency of $4 \mathrm{~Hz}$ for $2.0-2.5 \mathrm{~min}$, synchronized with the spray start, and running for the duration of the application. The ultrasonic anemometer measures velocity in 3 dimensions with the capability to resolve 3 components into resultant velocity and direction along 2 axes. The first axis (horizontal wind direction) is the normal compass azimuth in degrees starting from north at $0^{\circ}$; in these experiments, the instrument was installed to read north as the sprayer travel 


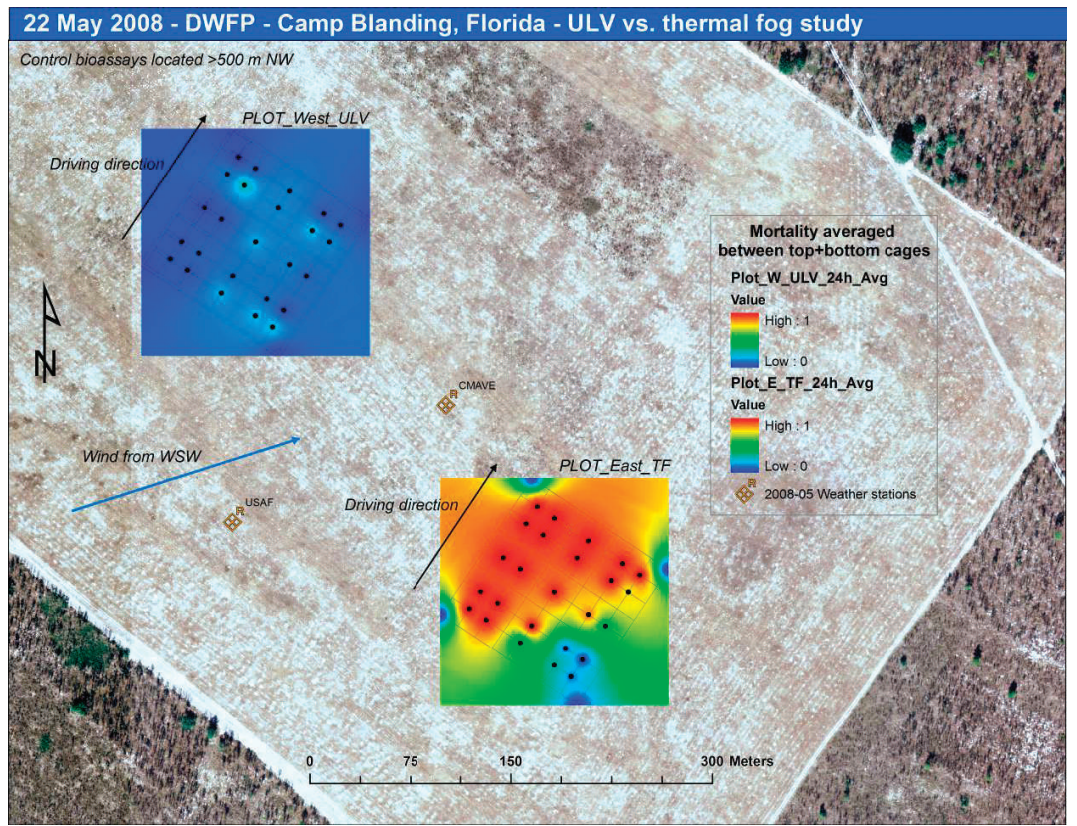

Fig. 4. Mortality comparisons of ULV (northwest plot at the upper left) and thermal fog (southeast plot at the lower right) applications using malathion on caged Ae. taeniorhynchus under hot-humid conditions conducted in May 2008 at Camp Blanding, FL, are depicted in a GIS. In the interpolated mortality surfaces, reds symbolize 80$100 \%$ mortality, yellows symbolize $70-80 \%$ mortality, greens symbolize $30-70 \%$ mortality, and blues symbolize $0-$ $30 \%$ mortality.

direction, which was approximately north, as opposed to true north. The second axis (vertical wind direction) is an angle relative to the ground surface, with $0^{\circ}$ representing wind parallel to the ground surface, positive angles indicating wind moving upward, and negative angles indicating wind moving downward.

\section{Mapping bioassay efficacy data}

We mapped bioassay mortality data on the DOQs of the test areas in the ArcGIS 9.2 GIS by assigning the values of the mean 24-h mortality frequency between the upper and lower cages to their respective pole positions and carrying out an inverse distance-weighted (IDW) interpolation analysis for each grid. Interpolation by IDW estimates a continuous surface using actual measured values from a defined set of points and is designed to constrain the effect of more distant points on the estimation of a value at any given point. The IDW parameters were set to the default exponent of distance of 2 , which controlled the significance of surrounding points on the interpolated value, and a fixed search radius of $400 \mathrm{~m}$ from each interpolated point to take into account all values in a grid. To enhance visualization of the interpolated surface, we added null values to corners of a square $15 \mathrm{~m}$ out from each side of the grid. We color-coded the resulting interpolated surface using a red to blue color ramp, where reds symbolized $80-100 \%$ mortality, yellows symbolized 70-80\% mortality, greens symbolized $30-70 \%$ mortality, and blues symbolized $0-30 \%$ mortality.

\section{RESULTS}

\section{Weather conditions}

Wind speed, horizontal wind direction, and vertical wind direction are given in Fig. 6 for the Florida and California sites. At the Florida site, temperature and relative humidity were $78^{\circ} \mathrm{F}$ $\left(25.5^{\circ} \mathrm{C}\right)$ and $82 \%$, respectively, during the application, and the wind speed ranged from 1.1 to $4.4 \mathrm{mph}$ with an average of $2.5 \mathrm{mph}$. The horizontal wind direction ranged between $189^{\circ}$ and $243^{\circ}$ with an average of $213^{\circ}$, indicating that wind was pushing spray into test grids at an angle of $9-63^{\circ}$ from behind the sprayer. The vertical direction ranged from $-24^{\circ}$ to $22^{\circ}$ with an average of $-1.3^{\circ}$. At the start of the trial wind speed declined dramatically as the vehicles with ULV and thermal fog equipment drove northeast, as indicated by the black arrows in Fig. 4.

At the California site, the temperature and relative humidity were $99^{\circ} \mathrm{F}\left(37.2^{\circ} \mathrm{C}\right)$ and $15 \%$, respectively, during the application, and the wind speed ranged from 0.8 to $9.5 \mathrm{mph}$ with an average of $5.0 \mathrm{mph}$. The horizontal wind 


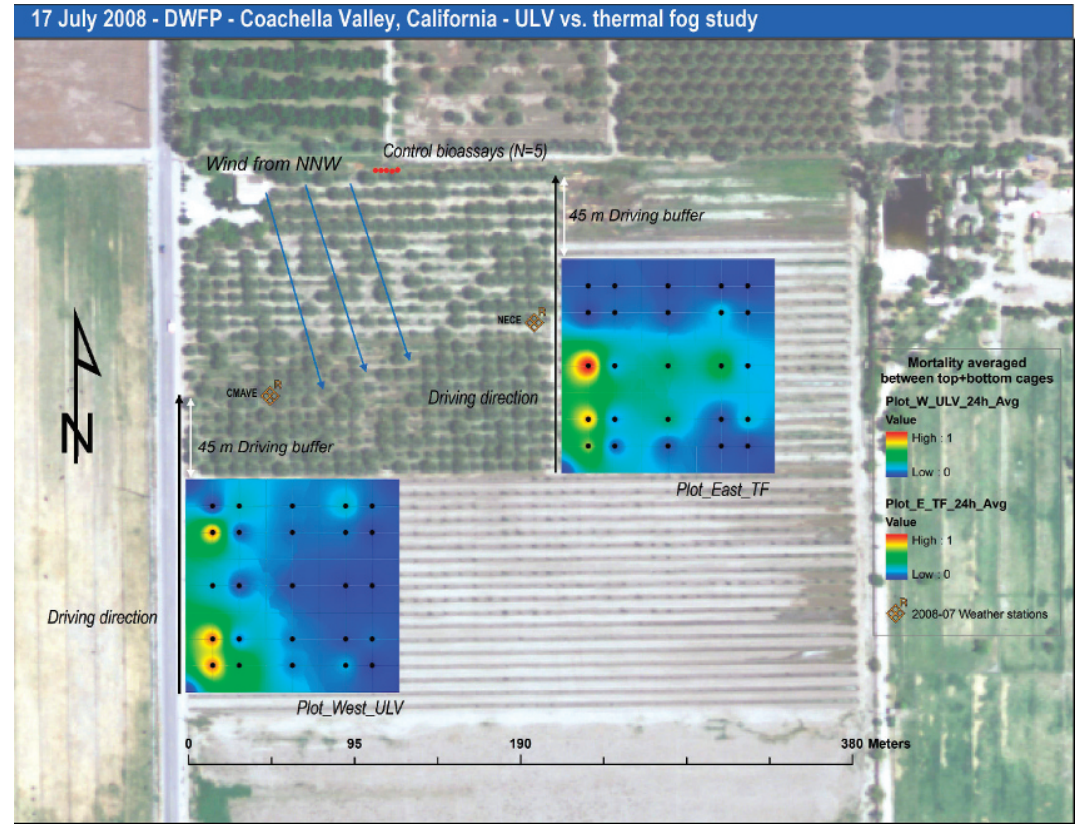

Fig. 5. Mortality comparisons of ULV (southwest plot at the lower left) and thermal fog (northeast plot at the upper right of the image) applications using malathion on caged Cx. quinquefasciatus conducted in July 2008 under extremely hot-dry conditions in the southern California desert in the Coachella Valley, are depicted in a GIS. Refer to Fig. 4 legend for key to interpolated mortality surfaces.

direction ranged between $325^{\circ}$ and $411^{\circ}\left(51^{\circ}\right.$ to $\mathrm{NE}$; any direction in NE has been plotted as $360^{\circ}+$ for clarity) with an average of $351^{\circ}$, indicating that wind was between $9^{\circ} \mathrm{NW}$ and $51^{\circ} \mathrm{NE}$. This range of wind directions indicated that wind was pushing spray between a range of angles of $9^{\circ}$ into and $51^{\circ}$ away from the test grids. The vertical direction ranged from $-54^{\circ}$ to $36^{\circ}$ with an average of $1.6^{\circ}$. At the start of the trial wind speed was variable and changed direction from the northwest to almost from due north (parallel to the northerly drive direction) and then back to a north-northwesterly direction as the vehicles with ULV and thermal fog equipment drove northward, as indicated by the black arrows in Fig. 5.

\section{Patterns of mortality: Camp Blanding site}

Mortality in the north, west, and east sections of the thermal fog spray plot (Fig. 4) was high (96-100\%) but declined to low values $(5-50 \%)$ in the southern portion of the plot; mortality in the ULV plot was uniformly low $(0-27 \%)$. In both ULV and thermal fog plots, at posts where mortality was observed in sentinel mosquitoes, mortality had occurred in both upper and lower cages. Within a margin of $\sim 25 \%$, equivalent mortality in both ULV and thermal fog plots was observed in caged mosquitoes positioned at both the $0.3 \mathrm{~m}$ and $1.2 \mathrm{~m}$ heights. Notable exceptions were observed only in the thermal fog plot, at positions $\mathrm{C} 1, \mathrm{D} 1$, and $\mathrm{E} 4$, where mortality was $>50 \%$ higher in the upper cage for $\mathrm{C} 1$, and $\sim 40 \%$ higher in the upper cages for D1 and E4. No fluorescent aerosol droplets were observed on ribbons under light from UV flashlights in the ULV plot; however, fluorescent droplets were observed on ribbons in the thermal fog plot. Mean mortality in the control sentinel mosquitoes at $24 \mathrm{~h}$ averaged between top and bottom cages was $2 \%$ with a range of $0-5 \%$.

\section{Patterns of mortality: Coachella Valley site}

Mortality was observed throughout the thermal fog spray plot but was highest in the southwest quadrant and fairly uniformly high throughout the southern half of this study plot (Fig. 5). Mortality was recorded as much as $350 \mathrm{ft}$ $(105 \mathrm{~m})$ into the date palm canopy to the east of the spray line in the thermal fog plot. Mortality in the ULV plot was highest along the line of cages $50 \mathrm{ft}(15 \mathrm{~m})$ from the spray line, ranging from $2 \%$ at positions $\mathrm{A} 5$ and $\mathrm{A} 3$ to $87-88 \%$ at positions A1, A2, and A4. Mortality was observed throughout the date palm canopy in this plot, but declined rapidly to low levels after $100 \mathrm{ft}$ $(30 \mathrm{~m})$. Within a margin of $\sim 25 \%$, equivalent mortality in both ULV and thermal fog plots was observed in caged mosquitoes positioned at both the $0.3 \mathrm{~m}$ and $1.2 \mathrm{~m}$ heights, and droplets were clearly visible on the deployed ribbon when illuminated with UV flashlights at heights ranging 
A

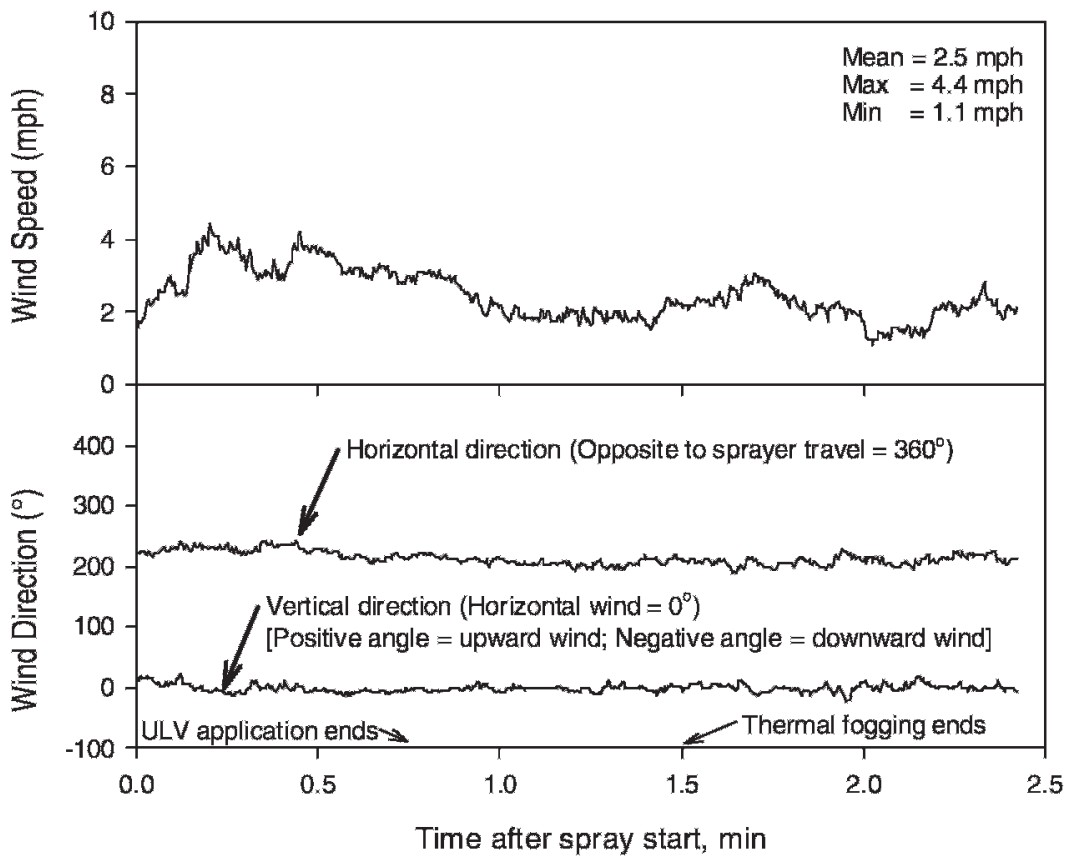

B

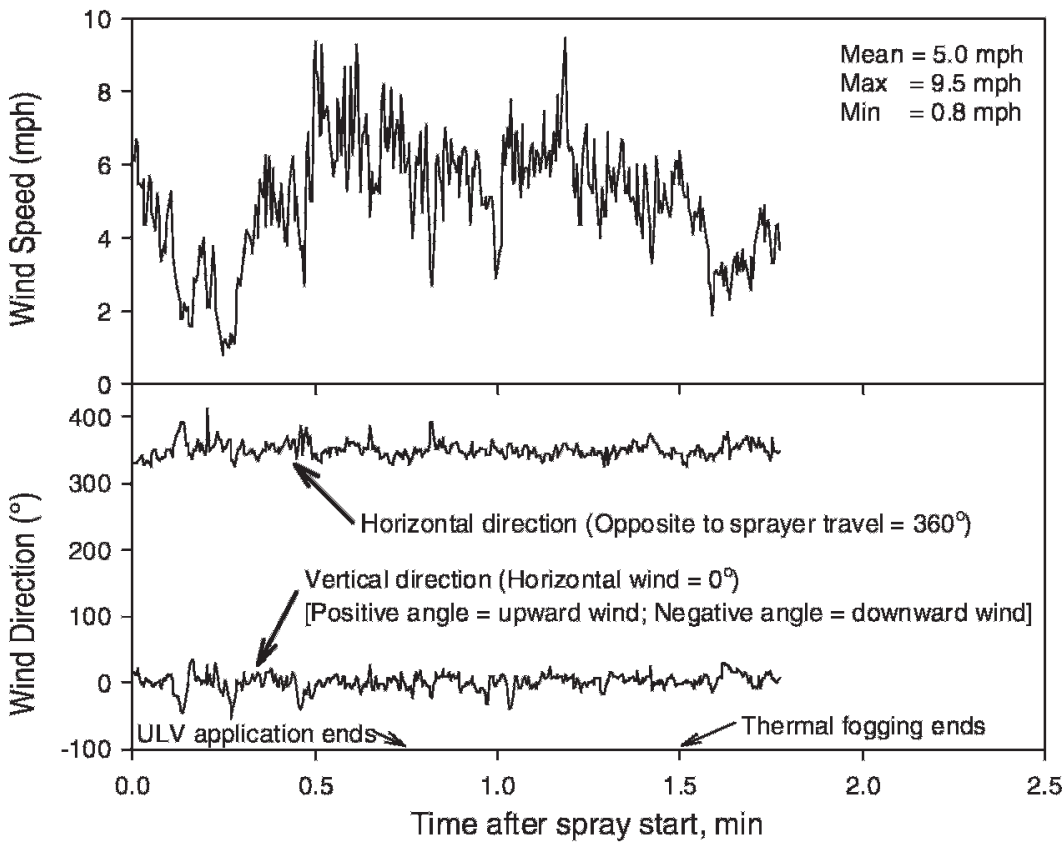

Fig. 6. Wind speed and direction during spray application: (A) Camp Blanding, FL; (B) Coachella Valley, CA.

from 0.3 to $3 \mathrm{~m}$. Notable exceptions in the ULV plot were positions $\mathrm{A} 3$, B1, and $\mathrm{B} 5$, where mortality was $>80 \%$ higher in upper cages for A3 and B1, and $>50 \%$ lower for B5. Similarly, in the thermal fog plot, mortality was greater by more than $\sim 60 \%$ in upper cages at positions $\mathrm{C} 2$, C3, D3, and D4, and greater in the upper cage by nearly $40 \%$ at position E3; whereas mortality was 
nearly $40 \%$ higher in the lower cage at position E2. Pre-spray catch of Ps. columbiae from the 6 EVS traps totaled 16,800 females; post-spray catch from the 6 traps totaled 3,098 females. Mean mortality in the control sentinel mosquitoes at $24 \mathrm{~h}$ averaged between top and bottom cages was $1 \%$, with a range of $0-5 \%$.

\section{Comparative deposition from ULV and thermal fogger sprayers: Camp Blanding}

On average, the ULV application resulted in $163.4 \mathrm{ng} / \mathrm{cm}^{2}$ deposition, and the thermal fog application resulted in $173.0 \mathrm{ng} / \mathrm{cm}^{2}$ deposition (Table 1). Deposition data in Table 1 also show that the deposition from the ULV application, averaged for all ribbon ladder heights, increased with increasing distance from spray line. In the case of the thermal fog application, the trend was reversed. Figure 7A shows active ingredient deposition at different heights and distances from the spray line, as captured with the ribbon ladders. The data indicate that the deposition from the ULV application was greater at lower heights, especially on the 2 ribbon ladders furthest from the spray line. The deposition from thermal fog was greater at upper heights on the 3 ribbon ladders closest to the spray line.

The active ingredient deposition was converted to droplet density (number of droplets $/ \mathrm{cm}^{2}$ ) based on the active ingredient contained by a droplet equivalent to volume median diameter $\left(\mathrm{Dv}_{0.5}\right)$ generated by each application system. For this conversion, the $\mathrm{Dv}_{0.5}$ for ULV application and thermal fogger were $14.6 \mu \mathrm{m}$ (Hoffmann et al. 2007a) and $3.1 \mu \mathrm{m}$ (Hoffmann et al. 2008), respectively. The resulting droplet densities from 2 application systems at different heights and distances from the spray line are presented in Fig. 7B. It should be noted that droplets from ULV number in the 100s while droplets from thermal fogger number in the 1,000s. Even at locations of significantly higher deposition from ULV, droplet density from the thermal fogger application is significantly higher than the droplet density from the ULV application.

\section{Comparative deposition from ULV and thermal fogger sprayers: Coachella Valley site}

The overall deposition from the ULV application was $5.6 \mathrm{ng} / \mathrm{cm}^{2}$, and the deposition from the thermal fog application was $5.8 \mathrm{ng} / \mathrm{cm}^{2}$ (Table 1). Deposition at the Florida site had been over 30fold greater; at the California site, much of the material appeared to have been lifted away from the spray area and not deposited, although sufficient material fell and caused some mortality. As shown in Table 1, the deposition as measured with the ribbon ladders from the California ULV application, unlike the ULV application in 
A

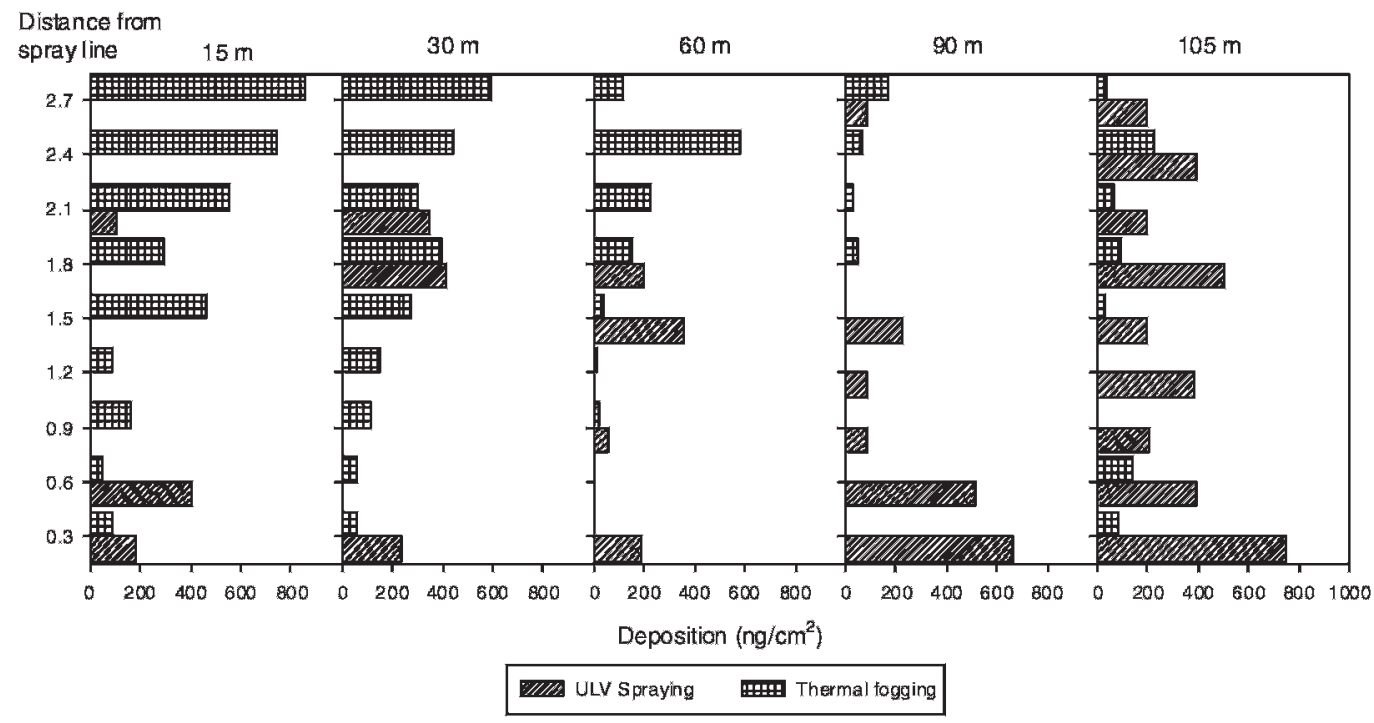

B

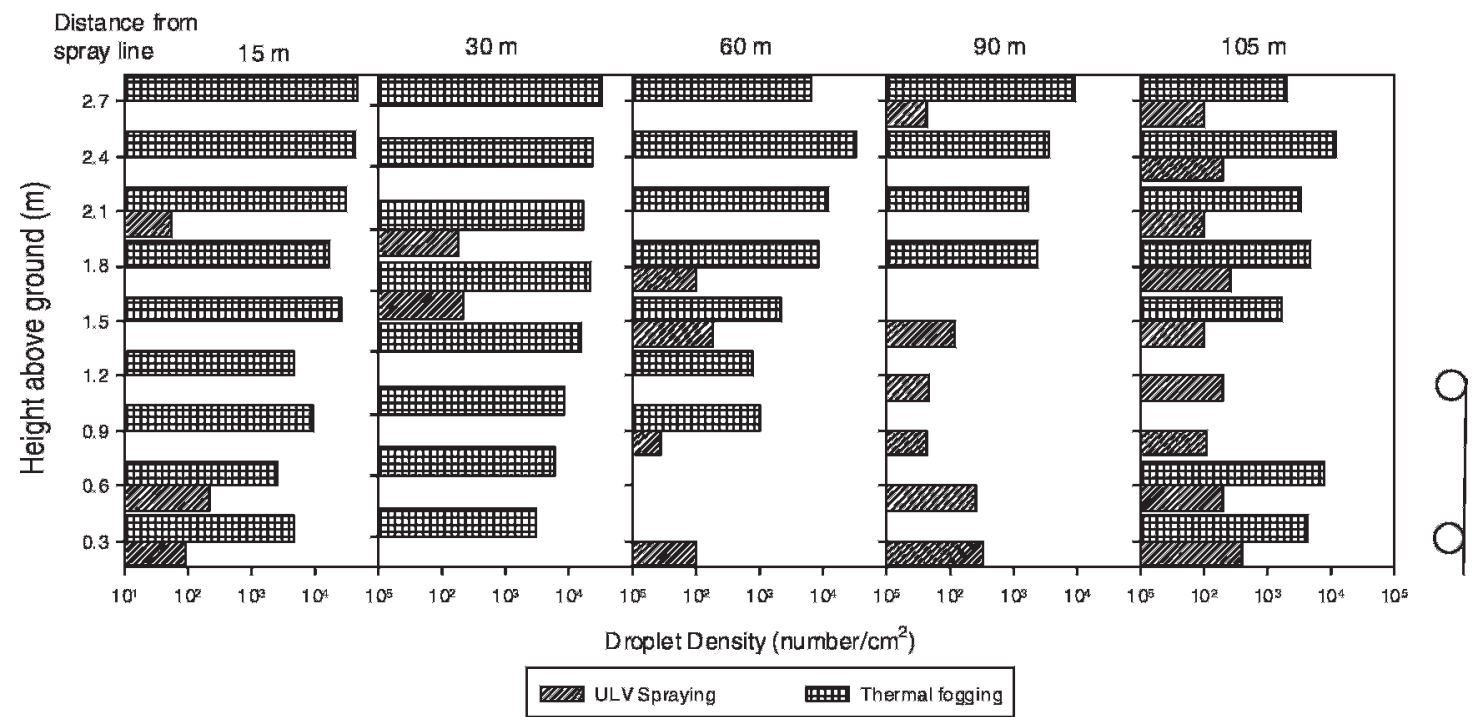

Fig. 7. Deposition data from the Camp Blanding, FL, trial. The icon, drawn to scale, to the right of each chart represents a post with sentinel cages at the $0.3 \mathrm{~m}$ and $1.2 \mathrm{~m}$ heights. (A) Deposition of active ingredient from 2 application systems at heights and distances from spray line. (B) Droplet densities from 2 application systems at heights and distances from spray line.

Florida, decreased with increasing distance from the spray line. However, similar to the Florida trial, the California thermal fog application resulted in the average deposition decreasing with increasing distance from the spray line. Figure 8A shows very low deposition at distances from spray line beyond $50 \mathrm{ft}(15 \mathrm{~m})$. At $\geq 50 \mathrm{ft}(15 \mathrm{~m})$ from the spray line the deposition was, in general, similar from the 2 application systems. On the other hand, Fig. 8B shows a large difference in droplet density between the 2 application systems for the California trial, with the thermal fog producing significantly more drops at all distances up to $90 \mathrm{~m}$ from the spray line. 


\section{A}

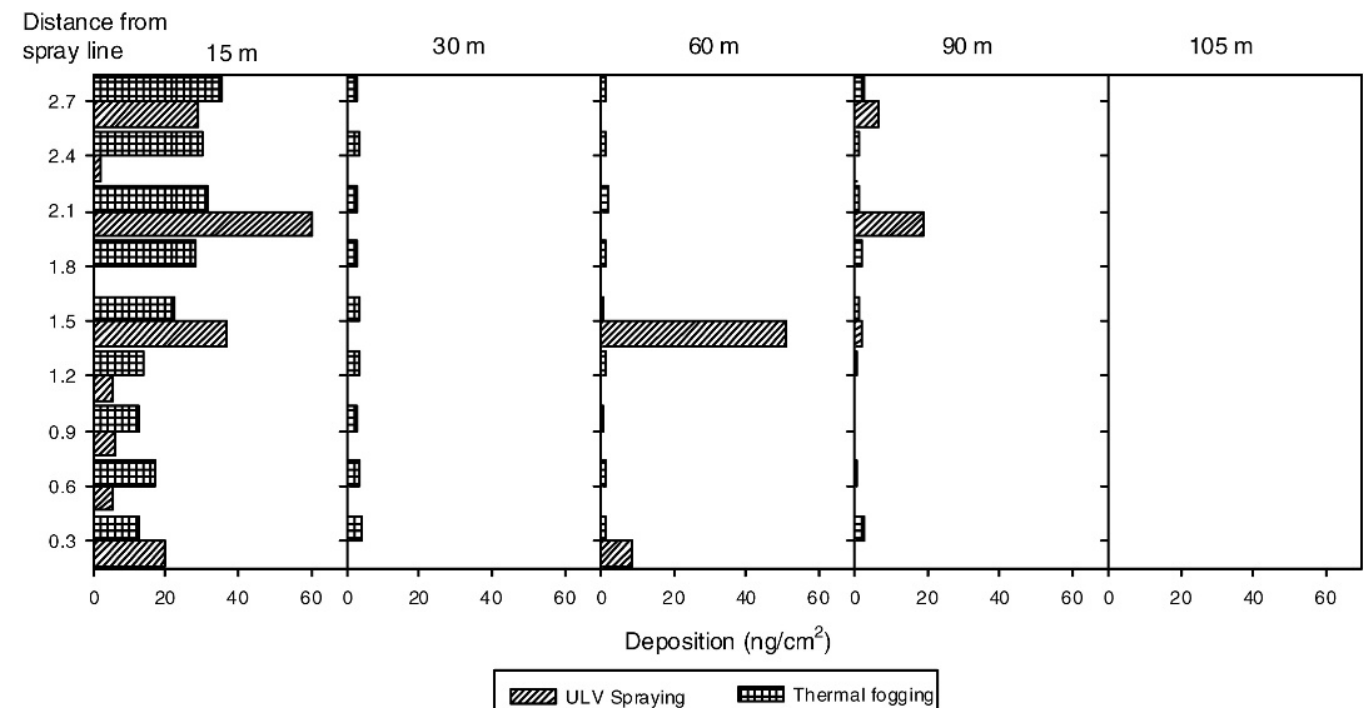

B

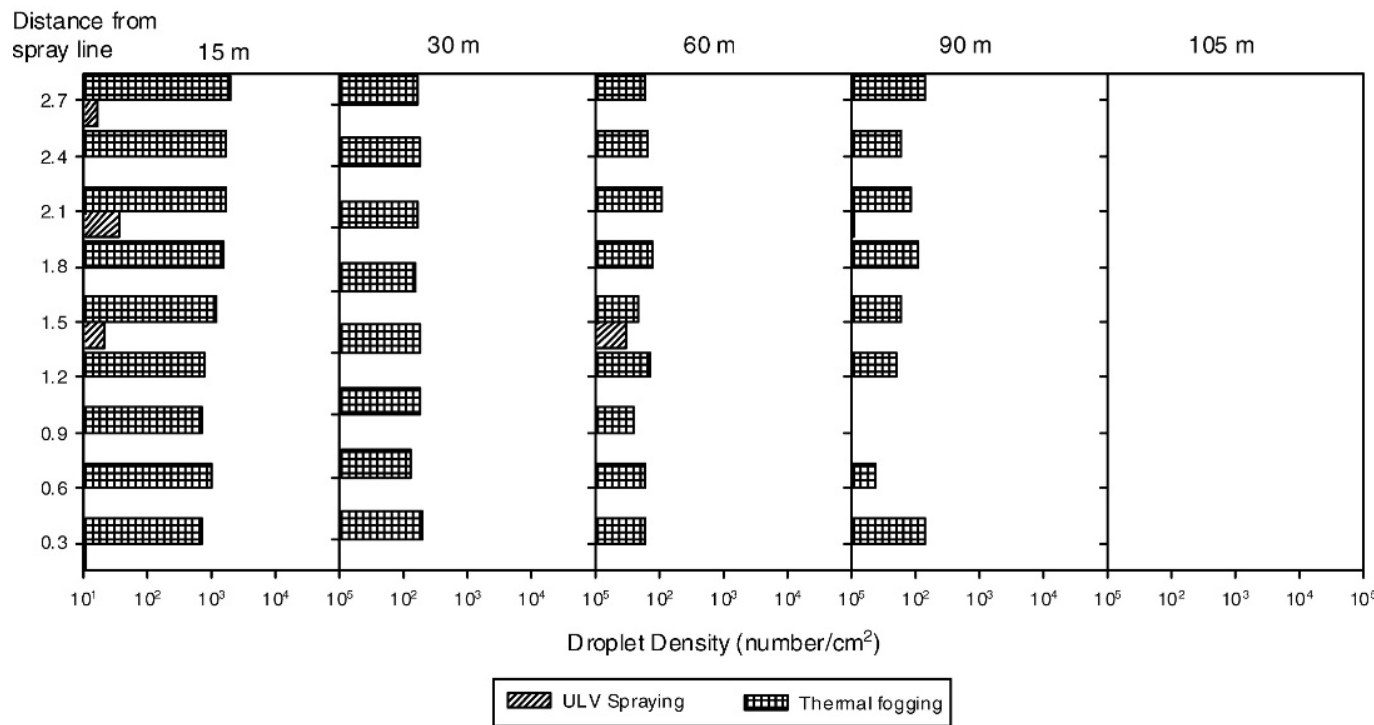

Fig. 8. Deposition data from the Coachella Valley, CA, trial. The icon, drawn to scale, to the right of each chart represents a post with sentinel cages at the $0.3 \mathrm{~m}$ and $1.2 \mathrm{~m}$ heights. (A) Deposition of active ingredient from 2 application systems at heights and distances from spray line. (B) Droplet densities from 2 application systems at heights and distances from spray line.

\section{DISCUSSION}

With respect to spatial spread and depth of penetration, as measured by numbers and locations of sentinel Ae. taeniorhynchus killed, thermal fog application of malathion was demonstrated to be markedly more efficacious, compared to the
ULV application, in a hot-humid, low wind, open habitat environment at Camp Blanding, FL (Fig. 4). Thermal fog application of malathion was demonstrated to be moderately more efficacious, compared to the ULV application, in killing caged $C x$. quinquefasciatus mosquitoes, penetrating at least $350 \mathrm{ft}(105 \mathrm{~m})$ into a date palm 
plantation in a hot-dry desert environment in the Coachella Valley in southern California (Fig. 5). In both the Florida and California test areas, mortality in the sentinel control mosquitoes was extremely low $(\leq 5 \%)$, indicating that the toxic aerosols had not reached the control mosquitoes, and also indicating that mortality in sentinel mosquitoes was due to the pesticide application.

Deposition was approximately 30 -fold greater at the Florida site when compared to the California site, presumably because of multiple factors, including much lower temperatures and higher humidities, much lower average horizontal wind speed (0.5-fold lower), negative average vertical wind direction, and only moderate wind turbulence. At the California site, much of the material in both plots was lifted and moved away from the sentinel grids, although mortality still occurred heterogeneously throughout both plots. On the other hand, deposition increased further into the ULV plot at the Florida test, suggesting that droplets may have lifted for a short time but then diffused to a wider area that was reflected by peak mortality for the grid (11-20\%) along the C1-C5 and D1-D4 line of cages, although singular instances of $12-20 \%$ mortality were also seen at positions A4, B4, E1, and E4.

A noteworthy outcome of this study is that active ingredient deposition was not necessarily predictive of mortality (Table 1). For example, in spite of instances of equal or lesser amount of deposition in both trials, the thermal fog application consistently resulted in higher levels of mosquito mortality than from the ULV application. This difference in deposition was significant in the Florida trial for distances $\geq 300 \mathrm{ft}(90 \mathrm{~m})$ from the spray line in favor of ULV (Table 1), yet the thermal fog application resulted in a much greater and spatially more extensive mortality. Similarly, the deposition in the California trial at $200-300 \mathrm{ft}(60-90 \mathrm{~m})$ for ULV was double or triple that of thermal fog (Table 1), yet the mortality at these ribbon ladder positions was significantly higher for the thermal fog application. This incongruity could be attributed to 2 factors. First, taking, for example, the Florida data shown in Fig. 7, the droplet density for the thermal fog application $\left(\mathrm{Dv}_{0.5}=3.1 \mu \mathrm{m}\right)$ was 104 times more than that for the ULV application $\left(\mathrm{Dv}_{0.5}=14.6 \mu \mathrm{m}\right)$. This means that, even though the average total deposition in $\mathrm{ng} / \mathrm{cm}^{2}$ from each technology is not greatly different (Table 1), there is at least a 100 -fold greater chance that a droplet will come in contact with a mosquito in the sentinel cage in a thermal fog application versus a ULV application. Second, certain modes of air turbulence help spread any aerosol cloud to a larger area: for instance, turbulence of a scale larger than the spray cloud moves the whole cloud with it, turbulence of a scale smaller than the cloud helps to spread the cloud and increase its size. Thus, under low wind conditions, as found during applications during the Florida trial, small-scale turbulence is prevalent, and the aerosol cloud spreads out and disperses in space. Evidence in support of this scenario is found in the general equality of mortality in upper and lower cages in the thermal fog plot in the Florida test, as opposed to more frequent instances of heterogeneous upper and lower mortality frequencies in the thermal fog plot in the California test where wind conditions were more harsh. Given the relatively small size of droplets in thermal fog application, the small magnitude of turbulent velocity could have propelled the droplets around and into the cages. On the other hand, droplets from the ULV application would have required a relatively higher magnitude of turbulence for dispersal to equal that experienced by the thermal fog aerosol cloud. Given the sudden drop in wind velocity just after the ULV treatment began, the majority of the ULV droplets simply drifted to the ground and did not reach sentinel cages in great numbers.

The results also indicate that a considerably smaller amount of active ingredient (and smaller droplet size) is sufficient to kill a mosquito as opposed to earlier findings (Himel 1969, Haile et al. 1982).

Following the trial at the Camp Blanding site we hypothesized factors that may have contributed to the difference in performance between the ULV and the thermal fog treatments. One factor was the possibility that, relative to the capacity of the reservoir tank, a small amount of Fyfanon ULV was used in the 18-20, and the slightly bouncing drive over uneven ground at the test site may have caused intermittent delivery of the malathion. We returned to the test site in daylight and ran the 18-20 on the spray line using the same vehicle and the same volume of pesticide, specifically observing the output from the ULV nozzle, and found that the 18-20 produced a satisfactory, even flow despite the bounces and the low volume of material in the reservoir. Another factor hypothesized to contribute to differences in efficacy between the ULV and the thermal fog technology in the Florida test was the possibility that the diesel present in the aerosol produced by the Silver Cloud was toxic to mosquitoes or enhanced the toxicity of the malathion in the burned solution. Following the technique described in Pridgeon et al. (2008) we carried out a topical application screening of unburned diesel, diesel burned through a thermal fogger, technical malathion, unburned $1 \%$ Fyfanon ULV-diesel solution, and 1\% Fyfanon ULV-diesel solution burned through a thermal fogger. These compounds had been collected during the mass equipment tests documented in Hoffmann et al. (2008) and stored in a refrigerator. The mosquito species selected for testing 
Ae. taeniorhynchus

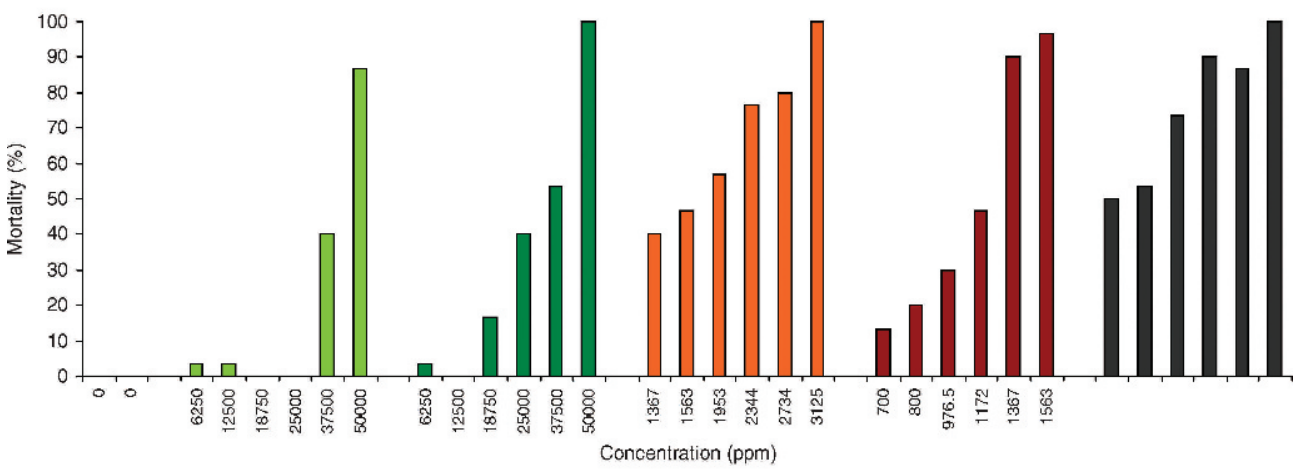

Cx. quinquefasciatus

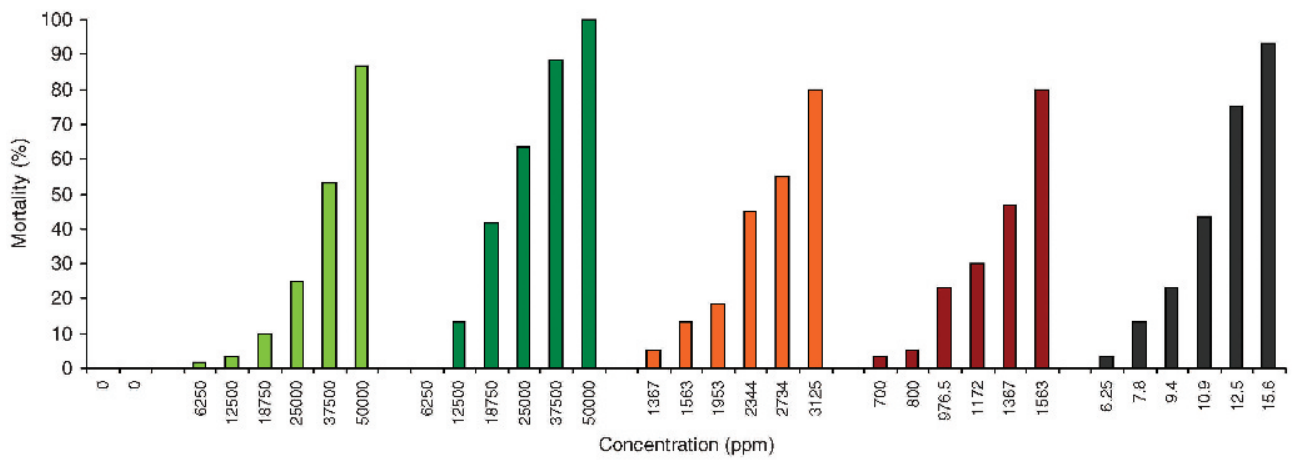

$\square$ Untreated

Acetone

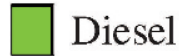

Diesel burned

\section{Fyfanon (1\%)}

\section{Fyfanon burned (1\%)}

\section{Malathion (technical)}

Fig. 9. Results of topical application of diesel-formulated Fyfanon before and after burning through a thermal fogger. Experiments were independently replicated 3 times as completely randomized designs testing 30 insects for each of 6 concentrations for each replicate according to the methodology of Pridgeon et al. (2008). Bioassays were held at $27^{\circ} \mathrm{C}$ for $24 \mathrm{~h}$ prior to scoring.

matched the species used in the Florida and California trials. The topical application screening consists of applying small droplets of compounds directly on the thorax of test mosquitoes and recording mortality over time. The results shown in Fig. 9 indicate that diesel has essentially no toxicity on the tested mosquito species: the lowest concentration of diesel caused close to zero mortality, whereas a concentration of Fyfanon ULV-diesel at half that of the raw diesel caused $70-100 \%$ mortality depending on the species tested.
Overall, these findings echo the results of many of the seven comparative studies cited earlier: thermal fog applications may result in equal or greater mortality against sentinel mosquitoes when compared to ULV applications. In addition, the present study provides evidence that the superiority of thermal fog over ULV with respect to mortality in sentinel mosquitoes holds up across 2 very different environments. Importantly, given the specific questions of the present study regarding potential efficacy in current US military scenarios, ULV did not function as well 
as thermal fog in the hot-dry desert environment. Another factor should enter into consideration for military use of one or the other of these technologies: in a hostile military environment the opportunities for an aerosol public health insect control operation may be extremely narrow. Weather events took place in each tested environment that demonstrated the flexibility of thermal fog and the limitations of ULV. As compared in the simultaneous application of ULV aerosols, the thermal fog aerosol resulted in high kill throughout more than $50 \%$ of the target area despite a sudden loss of wind energy in the Florida trial, and the thermal fog aerosol resulted in kill further and wider through an area with tall vegetation despite high wind energy and sudden changes in wind direction in the California trial. If these 2 events had taken place in tactical scenarios and ULV had been the technology of choice for public health insect control operations, the opportunities to effectively control disease vectors or nuisance insects could have been lost. There is clearly an advantage to using a quiet, invisible technology such as ULV aerosol in a hostile military environment; however, this technology should also be effective against the target insects, and a new evaluation may be needed to weigh the costs and benefits of the noisy clouds of the thermal fog. For instance, ULV does put out much smaller amounts of material into the environment, but poor performance of an application could require multiple reapplications and the low volume advantage diminishes, not to mention increased exposure of personnel to potentially hostile contact during repeated visits to the same area.

Although these results indicate that more work should be done to further evaluate thermal fog efficacy in desert environments, future studies should also look at efficacy against wild mosquito populations as well as sentinel mosquitoes. The trap counts for Ps. columbiae in the California trial before and after the applications suggest that applications were effective against real-world populations as well as sentinels, but the arrangement of traps and aerosol test grids did not permit us to determine which technology may have had a greater effect on reductions in the wild populations. Future studies should also look at a variety of ULV and thermal fog equipment, as well as pesticides, selected from the Department of Defense lists (Armed Forces Pest Management Board 2010); and future studies should also take place in arid-hot areas with wild populations of Old World mosquitoes and sand flies, such as those in Kenya or Egypt, and eventually fielded for tests in-theater with the US military. Efforts should be made to perform spray trials through sentinel grids in a variety of vegetation densities and/or profiles in desert environments, and if one spray technology consistently outperforms the other, efforts should be focused on optimization of that spray technology. Optimization of a spray technology may include trials with a range of nozzles, pesticide dilutions or formulations, timing and speed of delivery, or machine settings, or it may include trials with experimental pesticides or spray equipment.

\section{ACKNOWLEDGMENTS}

This research was supported by the Department of Defense (DoD) through the Deployed War Fighter Protection Program, and the U.S. Department of Agriculture (USDA) Agricultural Research Service. The use of equipment and products in this study does not constitute endorsement by the USDA, the DoD, or the US Navy. Technicians from the Coachella Valley Mosquito and Vector Control District and personnel from the California Department of Public Health and the University of California Davis Center for Vectorborne Diseases kindly provided expert assistance in the field.

\section{REFERENCES CITED}

Armed Forces Pest Management Board. 2010. DoD standard pesticides list [Internet]. [accessed April 30, 2010]. Available from: http://www.afpmb.org/ standardlist.htm.

Bunner BL, Perich MJ, Boobar LR. 1989. Culicidae (Diptera) mortality resulting from insecticide aerosols compared with mortality from droplets on sentinel cages. J Med Entomol 26:222-225.

Cope SE, Strickman DA, White GB. 2008. The Deployed Warfighter Protection Research Program: finding new methods to vanquish old foes. Army Med Dept J April-June:9-20.

Dalton R. 2008. Battlefield insectica. Nature 454:18-19.

Haile DG, Mount GA, Pierce NW. 1982. Effect of droplet size of malathion aerosols on kill of caged adult mosquitoes. Mosq News 42:576-583.

Himel CM. 1969. The optimum size for insecticide spray droplets. J Econ Entomol 62:919-925.

Hoffmann WC, Walker TW, Fritz BK, Gwinn T, Smith VL, Szumlas D, Quinn B, Lan Y, Huang Y, Sykes D. 2008. Spray characterization of thermal fogging equipment typically used in vector control. $\mathrm{J} \mathrm{Am}$ Mosq Control Assoc 24:550-559.

Hoffmann WC, Walker TW, Martin DE, Barber JAB, Gwinn T, Smith VL, Szumlas D, Lan Y, Fritz BK. 2007a. Characterization of truck-mounted atomization equipment typically used in vector control. $\mathrm{J} \mathrm{Am}$ Mosq Control Assoc 23:321-329.

Hoffmann WC, Walker TW, Smith VL, Martin DE, Fritz BK. 2007b. Droplet-size characterization of handheld atomization equipment typically used in vector control. J Am Mosq Control Assoc 23:315-320.

Holland JM, Jepson PC. 1996. Droplet dynamics and initial field tests for microencapsulated pesticide formulations applied at ultra low volume using rotary atomizers for control of locusts and grasshoppers. Pesticide Sci 48:125-134. 
LaMer VK, Hochberg S, Hodges K, Wilson I, Fales JA, Latta R. 1947. The influence of the particle size of homogeneous insecticidal aerosols on the mortality of mosquitoes in confined atmospheres. $J$ Colloid $\mathrm{Sci}$ 2:539-549.

Linley JR, Jordan S. 1992. Effects of ultra-low volume and thermal fog malathion, Scourge, and Naled applied against caged adult Culicoides furens and Culex quinquefasciatus in open and vegetated terrain. J Am Mosq Control Assoc 8:69-76.

Linthicum KJ, Allan S, Barnard D, Becnel J, Bernier U, Britch S, Clark G, Cooperband M, Geden C, Hogsette J, Kline D, Pereira R, Pridgeon J, Quinn B, Welch C, Zhao L. 2007. Mosquito and fly control research by the USDA-ARS Center for Medical, Agricultural and Veterinary Entomology (CMAVE) in the Deployed War-Fighter Protection (DWFP) program. Proc Pap Mosq Vector Control Assoc Calif 75:131-133.

Lofgren CS. 1970. Ultralow volume applications of concentrated insecticides in medical and veterinary entomology. Ann Rev Entomol 15:321-342.

Lothrop H, Lothrop B, Palmer M, Wheeler S, Gutierrez A, Gomsi D, Reisen WK. 2007a. Evaluation of pyrethrin and permethrin ground ultra-low volume applications for adult Culex control in rural and urban environments of the Coachella Valley of California. J Am Mosq Control Assoc 23:190-207.

Lothrop H, Lothrop B, Palmer M, Wheeler S, Gutierrez A, Miller P, Gomsi D, Reisen WK. 2007b. Evaluation of pyrethrin aerial ultra-low volume applications for adult Culex tarsalis control in the desert environments of the Coachella Valley, Riverside County, California. J Am Mosq Control Assoc 23:405-419.

Lothrop HD, Lothrop BB, Gomsi DE, Reisen WK. 2008. Intensive early season adulticide applications decrease arbovirus transmission throughout the Coachella Valley, Riverside County, California. Vector-Borne Zoonotic Dis 8:475-489.

Mount GA. 1998. A critical review of ultralow-volume aerosols of insecticide applied with vehicle-mounted generators for adult mosquito control. J Am Mosq Control Assoc 14:305-334.

Mount GA, Lofgren CS, Pierce NW, Husman CN. 1968. Ultra-low volume nonthermal aerosols of malathion and Naled for adult mosquito control. Mosq News 28:99-103.

Mount GA, Pierce NW, Lofgren CS, Gahan JB. 1970. A new ultra-low volume cold aerosol nozzle for dispersal of insecticides against adult mosquitoes. Mosq News 30:56-59.

Phanthumachinda B, Samuthrapngse W, Chanthon K. 1976. The control of field populations of Aedes aegypti by malathion, fenitrothion, bioresmethrin and pyrethrum ULV ground aerosols, and by malathion, DDVP and bioresmethrin thermal foggings. Bangkok, Thailand: Unpublished document WHO/VBC/ 76.651. 17 p.

Pridgeon JW, Pereira RM, Becnel JJ, Allan SA, Clark GG, Linthicum KJ. 2008. Susceptibility of Aedes aegypti, Culex quinquefasciatus Say, and Anopheles quadrimaculatus Say to 19 pesticides with different modes of action. J Med Entomol 45:82-87.

Rathburn CB, Boike AH. 1972. Ultra low volume tests of malathion applied by ground equipment for control of adult mosquitoes. Mosq News 32:183-187.

Rogers AJ, Beidler EJ, Rathburn CJ Jr. 1957. A cage test for evaluating mosquito adulticides under field conditions. Mosq News 17:194-198.

Rohe D, Fall RP. 1979. A miniature battery powered $\mathrm{CO}_{2}$ baited light trap for mosquito borne encephalitis surveillance. Bull Soc Vector Ecol 4:24-27.

Taylor RT, Schoof HF. 1971. Relative effectiveness of malathion thermal aerosols and ground-applied ULV against 3 species of mosquitoes. Mosq News 31:346-349.

Wirat S, Somkiat B, Banyong M, Mongkol G, Poonyos $\mathrm{R}$, Boonluan P. 1982. Tests of insecticides applied by ULV ground and thermal fogging equipment for the control of Aedes aegypti in Thailand. Bangkok, Thailand: Unpublished document WHO/VBC/ 82.869. 17 p. 